\title{
Studies of post heat treatment of L-PBF-Inconel 718: effects of hold time on microstructure, annealing twins and hardness
}

\author{
Wakshum M. Tucho ${ }^{1, \mathrm{a}^{*}}$, Vidar Hansen ${ }^{1, \mathrm{~b}}$ \\ ${ }^{1}$ Department of Mechanical and Structural Engineering and Materials Science, Faculty of Science and \\ Technology, University of Stavanger, 4036 Stavanger, Norway \\ awakshum.m.tucho@uis.no, ${ }^{\text {bvidar.hansen@uis.no }}$
}

\begin{abstract}
:
The widely adopted temperature for solid solution heat treatment (ST) for the conventionally fabricated Inconel 718 is $1100{ }^{\circ} \mathrm{C}$ for a hold time of $1 \mathrm{~h}$ or less. This ST scheme is however not enough to dissolve Laves and annihilate dislocations completely in samples fabricated with Laser metal powder bed fusion (L-PBF) additive manufacturing (AM)-Inconel 718. In spite this, the highest hardness obtained after aging for ST temperatures $\left(970-1250{ }^{\circ} \mathrm{C}\right)$ is at $1100{ }^{\circ} \mathrm{C} / 1 \mathrm{~h}$ [1]. The unreleased residual stresses in the retained lattice defects are potentially affecting other properties of the material. Hence, this work aims to investigate if a longer hold time of ST at $1100{ }^{\circ} \mathrm{C}$ will lead to complete recrystallization while maintaining the strength after aging or not. For this study, L-PBFInconel 718 samples were ST at $1100{ }^{\circ} \mathrm{C}$ at various hold times $(1,3,6,9,16$ or $24 \mathrm{~h})$ and aged to study the effects on microstructure and hardness. In addition, a sample was directly aged to study the effects of bypassing ST. The samples (ST and aged) gain hardness by $43-49 \%$. High density of annealing twins evolved during $3 \mathrm{~h}$ of ST and only slightly varies for longer ST.
\end{abstract}

\section{Introduction}

Inconel 718 is a high-strength, corrosion-resistant nickel-based superalloy used in the temperature range of -252 to $704^{\circ} \mathrm{C}$ [1]. The alloy is mainly used in aeronautics and in energy industries where high strength and corrosion resistance properties are prior requirements in severe environments. The optimum microstructure and mechanical strength of Inconel 718 is generally achieved after performing two-steps of post-heat treatments. These are solid solution heat treatment (ST) and aging (also known as precipitation hardening). The solid solution heat treatment is often performed in the temperature range of 970 to $1250{ }^{\circ} \mathrm{C}$ (the fusion temperature of Inconel 718 is $\approx 1300{ }^{\circ} \mathrm{C}$ ) for a few hours to dissolve Laves phase in order to release age-hardening constituents $(\mathrm{Nb}$, $\mathrm{Ti}$ and $\mathrm{Al})$ into solid solution in the matrix. Laves phase is a $\mathrm{Nb}$ and Ti-rich intermetallic compound represented as (Ni, $\mathrm{Cr}, \mathrm{Fe})(\mathrm{Nb}, \mathrm{Mo}, \mathrm{Ti})$. In addition, the dissolution of Laves phase is important since Laves is detrimental to the material tensile ductility, fatigue and creep rapture properties [1]. Dislocations and other lattice defects are also annihilated during solid solution heating depending on temperature and/or hold time. Aging is usually performed in two successive steps. The solution heat treated sample is first aged at $704-899{ }^{\circ} \mathrm{C}$ for a few minutes to several hours, and then at a lower temperature (593 $-704^{\circ} \mathrm{C}$ ) for another hold time [2]. Aging results in precipitation of ellipsoidal $\gamma^{\prime \prime}$ and spherical $\gamma^{\prime}$ phases into the Ni-rich $\gamma$-matrix. These two phases are expressed by the same formulation, given as 
$\mathrm{Ni}_{3} \mathrm{M}$. The $\gamma^{\prime \prime}$ phase is a $\mathrm{DO}_{22}$ body-centered tetragonal $\left(\mathrm{Ni}_{3} \mathrm{Nb}\right)$, whereas, the $\gamma^{\prime}$ phase is a primitive cubic $\mathrm{L}_{2}$ ordered intermetallic $\mathrm{Ni}_{3}(\mathrm{Nb}, \mathrm{Ti}, \mathrm{Al})$. In a thoroughly homogenised and aged Inconel 718, the volume fraction of $\gamma^{\prime \prime}$ precipitate is about four times larger than that of the $\gamma^{\prime}$ precipitate [3]. The $\gamma^{\prime \prime}$ precipitate is thus considered as the major strengthening phase. The volume fraction of $\gamma^{\prime \prime}$ phase precipitated however varies based on the quantity of $\mathrm{Nb}$ present in the solid solution [4]. It is therefore important to dissolve the Laves phase completely through solution heat treatment to make available enough $\mathrm{Nb}$ into the $\gamma$-matrix to realize precipitation of a large quantity of $\gamma^{\prime \prime}$ phase during aging.

In order to understand the changes after the heat treatments, it is important revisiting the microstructure of the as-printed Inconel 718. The fabrication process of Additive Manufacturing (AM), in general, and Laser metal powder bed fusion (L-PBF) in particular, involves very rapid heating and cooling process as compared to the conventional techniques. Consequently, the microstructure of L-PBF-Inconel 718 is quite different from the as-cast or wrought ones. The grain morphology of the L-PBF fabricated-Inconel-718 can be columnar, equiaxed or irregular structures. All the grains however consist of columnar and cellular subgrains. The cellular subgrains are the most dominant subgrains in Inconel 718 in the as-printed state. A typical Scanning Electron Microscopy (SEM) image of the as-printed L-PBF-Inconel 718 is shown in Fig. 1(a). The size of the cellular subgrains lies in the range of $0.3-1 \mu \mathrm{m}$. The columnar subgrains have high aspect ratio, but their average width is about the same size as that of the cellular subgrains. The subgrain boundaries are decorated with segregated phases, mainly the Laves phase. These phases are shown as white contrast along the subgrain boundaries of the electron backscatter diffraction (EBSD) image of Fig. 1(a).

In addition, the subgrain boundaries consist of high density of dislocation networks as revealed by TEM micrograph shown in Fig. 1(b). Because of these components, the subgrain boundaries usually appear diffused and thick. The classical theory of the growth of subgrains is explaining the formation of subgrains in terms of dislocation motion. According to Verhoeven [5], when dislocations are able to cross slips (high stacking fault energy), they tend to condense into tangles, which results in the creation of high and low density of dislocation regions. The regions with low density of dislocations are misoriented slightly $\left(<5^{\circ}\right)$ from each other and they are referred as subgrains. Whereas, the narrow region with high density of dislocations form the subgrain boundaries. The origin of subgrains in 3D-printed material is not yet clearly understood, apart from associating it to the repeated high heating/cooling rates the material experiences during the solidification process.

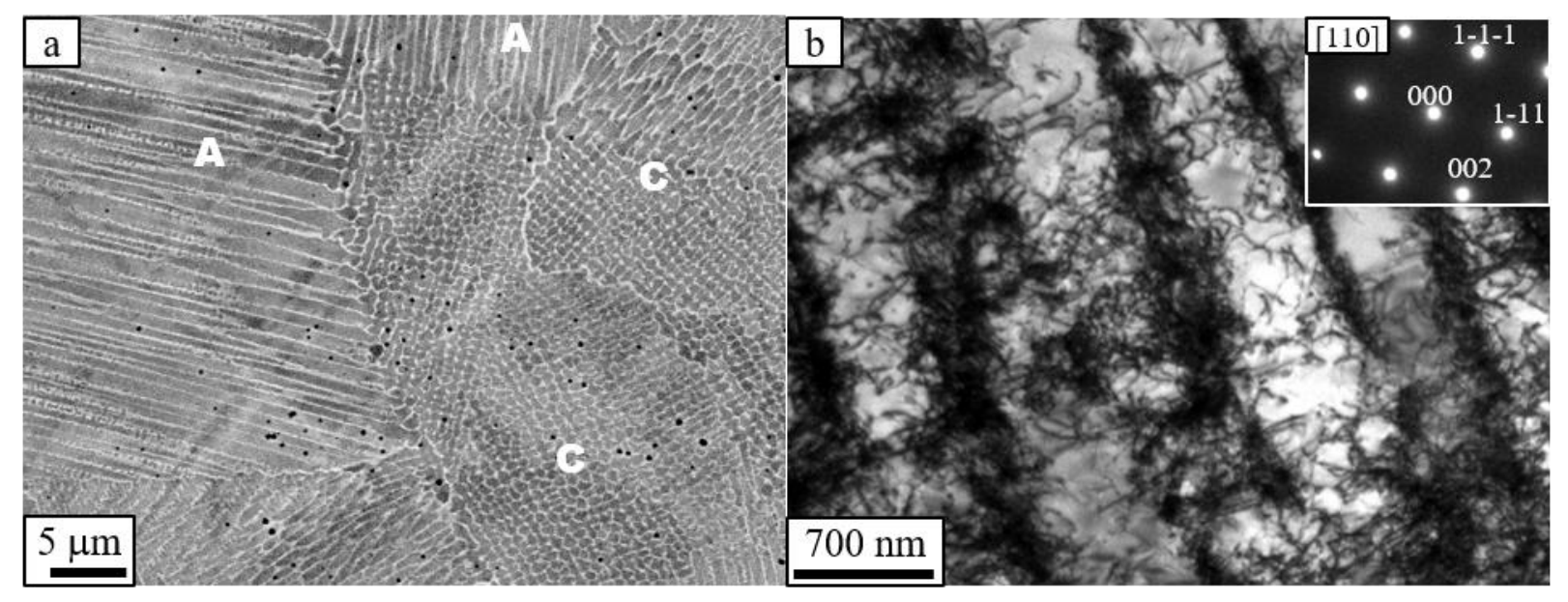

Fig. 1. Microstructure of as-printed L-PBF-Inconel 718. (a) SEM electron backscatter image showing cellular and columnar subgrains. The labels $\mathrm{A}$ and $\mathrm{C}$ indicate columnar and cellular subgrains, 
respectively. (b) TEM bright field image showing entangled high density of dislocations along the columnar subgrain boundaries. The inset is a selected area diffraction (SAD) pattern.

As shown above, the Laves phase is not a desirable component of the alloy. Lattice defects, primarily dislocations in the L-PBF-Inconel 718 are also potentially threatening mechanical properties since they are the sites of high stresses. However, short hold time $(1 \mathrm{~h})$ of ST at $1100{ }^{\circ} \mathrm{C}$, at which the maximum hardness attained [6] is not long enough to dissolve completely the Laves phase and annihilate the lattice defects. The features of the initial microstructure are generally retained after the ST for $1 \mathrm{~h}$. In addition, annealing twins are evolved in large quantities when Inconel 718 is ST at and close to $1100{ }^{\circ} \mathrm{C}[4,7]$ for hold times longer than $1 \mathrm{~h}[6]$.

Twin boundaries are low energy defects compared to grain boundaries but reports in literature showed that they do have both detrimental and beneficial effects on material properties. Improved tensile strength is one of the major beneficial effects observed due to the formation of annealing twins [8, 9]. According to Li and his co-workers [8], the improved tensile strength of austenitic (Fe-10Mn-4Al$0.3 \mathrm{C}$ ) is due to combined effects of grain refinement and formation of high density of annealing twins. Similarly, Chuang and his colleagues [9] showed simultaneous increment of tensile strength and elongation due to emerging of large amount of annealing twins in $\mathrm{Ag}-8 \mathrm{Au}-3 \mathrm{Pd}$ wire. Furthermore, the twin boundaries interaction with dislocation in $\mathrm{Fe}-\mathrm{Mn}-\mathrm{C}$ steel was found strengthening the material since the impeding process reduces the mean free path of dislocations [7]. On the negative side, twin boundaries are regarded as the initiation sites of fatigue cracks in Nickel-based superalloys $[10,11]$, in which case the formation of annealing twins is undesirable. Review of the impacts of twin boundaries on various technological materials, specifically that of the Ni-based alloys can be found in [12]. Considering the different effects of twins on material properties, it is essential to understand the parameters that influence the formation of annealing twins.

The aim of this study is thus to investigate if longer hold times of ST at $1100{ }^{\circ} \mathrm{C}$ will result in complete recrystallization while maintaining the strength of L-PBF-fabricated Inconel 718 or not. Likewise, the effects of hold time on the twin formation in relation to recrystallization and grain growth will be analyzed. The hardness and microstructure of directly aged sample is analyzed, if bypassing solid solution heat treatment would be an option or not. Microstructure and phase analysis are studied using Scanning Electron Microscopy, Transmission electron microscopy and X-Ray diffractogram. Vickers hardness tester is used for hardness measurement.

\section{Materials and Experimental Methods}

Inconel 718 cylindrical parts (12 cm long and $1.2 \mathrm{~cm}$ in diameter) were fabricated by PROMET AS using L-PBF $280^{\mathrm{HL}}$ machine equipped with $400 \mathrm{~W}$ fiber laser. Pre-alloyed powder with the nominal composition adopted from the standard specification for AM of Ni alloy (UNS N07718) [1] was used for the printing of the parts. The concentration ranges (in wt. \%) of the elements are Ni (50 - 55), Fe (11 - 22.4), Cr (17 - 21), Nb (4.8 - 5.5), Mo (2.8 - 3.3), Ti (0.7 - 1.2), Al (0.2 - 0.8), Co (1.0), $\mathrm{Si}(0.4), \mathrm{Mn}(0.4), \mathrm{Cu}(0.3)$. The particle size of the powder lies between 10 to $45 \mu \mathrm{m}$. The values of the basic printing parameters applied were laser beam power of $175 \mathrm{~W}$; scanning speed of $619 \mathrm{~mm} / \mathrm{s}$; hatching distance of $0.08 \mathrm{~mm}$ and layer thickness of about $0.03 \mathrm{~mm}$. The printing was done in argon atmosphere to reduce oxidation of the molten pool. The building platform was preheated to $200{ }^{\circ} \mathrm{C}$ to reduce stresses that may develop during printing. The printing direction was parallel to Z-axis (vertical plane) whereas, the deposited layers were parallel to the XY (horizontal) plane.

The as-printed (AP) samples were heat treated (solid solution and precipitation hardening) to investigate changes in microstructure and hardness as a function of ST hold time. Before aging, the 
samples were solid solution heat treated at $1100{ }^{\circ} \mathrm{C}$ for $1,3,6,9,16$ or $24 \mathrm{~h}$ hold time aiming to study the extent of stress relief and recrystallization. In addition, a sample was directly aged (DA) to analyze the effects of bypassing solid solution heat treatment. All the heat treatments were done in Nabertherm furnace equipped with a K type thermocouple. For the ST, the samples were introduced after stabilizing the furnace to the target temperature to avoid undesirable phase transformations at the lower temperatures. At the end of the hold time, the samples were removed from the furnace and quenched in cold water.

Following previous works $[2,13]$, the precipitation of the hardening phases was obtained after two successive steps of heat treatments adopted for conventionally fabricated Inconel 718 . The furnace is pre heated to the aging temperature prior to introducing the AP or ST samples. The aging treatment was done, first at $760^{\circ} \mathrm{C}$ for 10 hours, after which the samples were furnace cooled to $650^{\circ} \mathrm{C}$ and held for another 10 hours. At the end of the holding period, the samples were removed from the furnace and then cooled in air. Here after, ST refers to solid solution heat treatment and STA refers to the combined treatments of ST and aging. List of the specimens investigated, and heat treatment schemes are given in Table 1.

Table 1: Heat treatment scheme of the investigated samples.

\begin{tabular}{|c|c|c|c|c|c|c|c|c|}
\hline \multirow{3}{*}{ Specimen } & \multicolumn{3}{|c|}{$\underline{\text { Solid solution heat treatment }}$} & \multicolumn{5}{|c|}{ Precipitation hardening } \\
\hline & \multirow{2}{*}{$\begin{array}{l}\mathrm{T} \\
\left({ }^{\circ} \mathrm{C}\right)\end{array}$} & \multirow{2}{*}{$\begin{array}{l}\text { Hold time } \\
\text { (h) }\end{array}$} & \multirow[b]{2}{*}{ Cooling } & \multicolumn{2}{|c|}{ 1st aging } & \multicolumn{2}{|c|}{ 2nd aging } & \multirow[t]{2}{*}{ Cooling } \\
\hline & & & & $\mathrm{T}\left({ }^{\circ} \mathrm{C}\right)$ & $\begin{array}{l}\text { Time } \\
\text { (h) }\end{array}$ & $\begin{array}{l}\mathrm{T} \\
\left({ }^{\circ} \mathrm{C}\right)\end{array}$ & $\begin{array}{l}\text { Time } \\
\text { (h) }\end{array}$ & \\
\hline ST1 & \multirow[t]{12}{*}{1100} & 1 & quenched in & & & & & \\
\hline ST3 & & 3 & cold water & & & & & \\
\hline ST6 & & 6 & $\left(16-18^{\circ} \mathrm{C}\right)$ & & & & & \\
\hline ST9 & & 9 & & & & & & \\
\hline ST16 & & 16 & & & & & & \\
\hline ST24 & & 24 & & & & & & \\
\hline STA1 & & 1 & & 760 & 10 & 650 & 10 & \\
\hline STA3 & & 3 & & & & & & cooled \\
\hline STA6 & & 6 & & & & & & \\
\hline STA9 & & 9 & & & & & & \\
\hline STA16 & & 16 & & & & & & \\
\hline STA24 & & 24 & & & & & & \\
\hline DA & \multicolumn{3}{|c|}{ Direct aged } & & & & & \\
\hline $\mathrm{AP}$ & \multicolumn{7}{|c|}{ at treated) } & \\
\hline
\end{tabular}

Hardness tests were performed using a Vickers Struers DuraScan testing machine under $5 \mathrm{~kg}$ load. Phase analysis was done using powder X-ray diffractograms recorded with Bruker D8 X-Ray diffraction (XRD) equipment with $\mathrm{Cu}_{\mathrm{K} \alpha}$ radiation $(\lambda=1.54060 \AA$ ). The XRD was operating at $40 \mathrm{kV}$ and $25 \mathrm{~mA}$. The diffractograms were recorded between $35^{\circ}$ and $100^{\circ} 2 \theta$ at a step size of $0.034^{\circ}$. The microstructures of the specimens were analyzed with Scanning Electron Microscopy (SEM), Gemini SUPRA 35VP (ZEISS) equipped with EDAX Energy Dispersive X-ray Spectroscopy (EDS). For orientation mapping and quantitative analysis related to microstructure the electron backscatter diffraction (EBSD) system equipped on the SEM was implemented. Several scans of the samples were recorded and the EBSD acquired data were analysed with Orientation Imaging Microscopy (OIM) software. Phase and lattice defects were further investigated with Transmission Electron Microscopy (TEM), JEOL-2100 (LaB 6 filament), operating at $200 \mathrm{kV}$. For TEM analysis, thin foils were prepared, first by thinning down mechanically to a thickness of about $100 \mu \mathrm{m}$, and then punched $3 \mathrm{~mm}$ disks from the thin foils. These disks were then electropolished using a dual jet polishing system, Struers TENUPOL-5 operated at $13 \mathrm{~V}$ and $-30{ }^{\circ} \mathrm{C}$ in an electrolyte solution of $80 \%$ methanol 
and $20 \%$ perchloric acid. Sample preparation for investigation with SEM consisted of mechanical grinding, fine polishing and ultra-polishing with OP-S colloidal silica. After investigation with SEM, the samples were used for measurement of Vickers hardness testing.

\section{Results and discussions}

\subsection{Microstructure}

\subsubsection{Effects of solid solution heat treatment}

Solid solution heat treatment can lead to recovery, recrystallization and grain growth depending on temperature and/or hold time. This sub-section presents and discusses effects of heat treatments at different hold times on the as-printed microstructure. Fig. 2 shows SEM image that exhibits the microstructure of the samples ST at $1100{ }^{\circ} \mathrm{C}$, but with different hold times. For comparison, the microstructure of the as-printed sample is also presented. The grain structure of the as-printed L-PBF-Inconel 718 consists of columnar and cellular subgrains with a diameter ranging from 0.3 to $1 \mu \mathrm{m}$ as shown in Fig. 1. The subgrain boundaries are enriched in high density of dislocation networks and primary phases that give rise to higher strength than the as-cast material. The extent of changes in microstructure and dissolution of the primary phases are dependent on the hold time of solid solution heat treatment. After $1 \mathrm{~h}$ of ST at $1100{ }^{\circ} \mathrm{C}$, the sample undergone recovery and at the starting phase of recrystallization. Most of the sub-structures such as subgrains maintained their initial features. The Laves are largely dissolved, but not completely as shown in high magnification image of Fig. 3(a). Compared to the as-printed, the subgrain boundaries of ST1 appear very thin, because of lower concentration of segregated phases and dislocations. This shows that most of the subgrain boundaries have been sustained after the $1 \mathrm{~h}$ solutioning at $1100{ }^{\circ} \mathrm{C}$. Generally, the dissolution of the Laves phase and the annihilation of most of the dislocations preceded the elimination of the subgrain boundaries. 


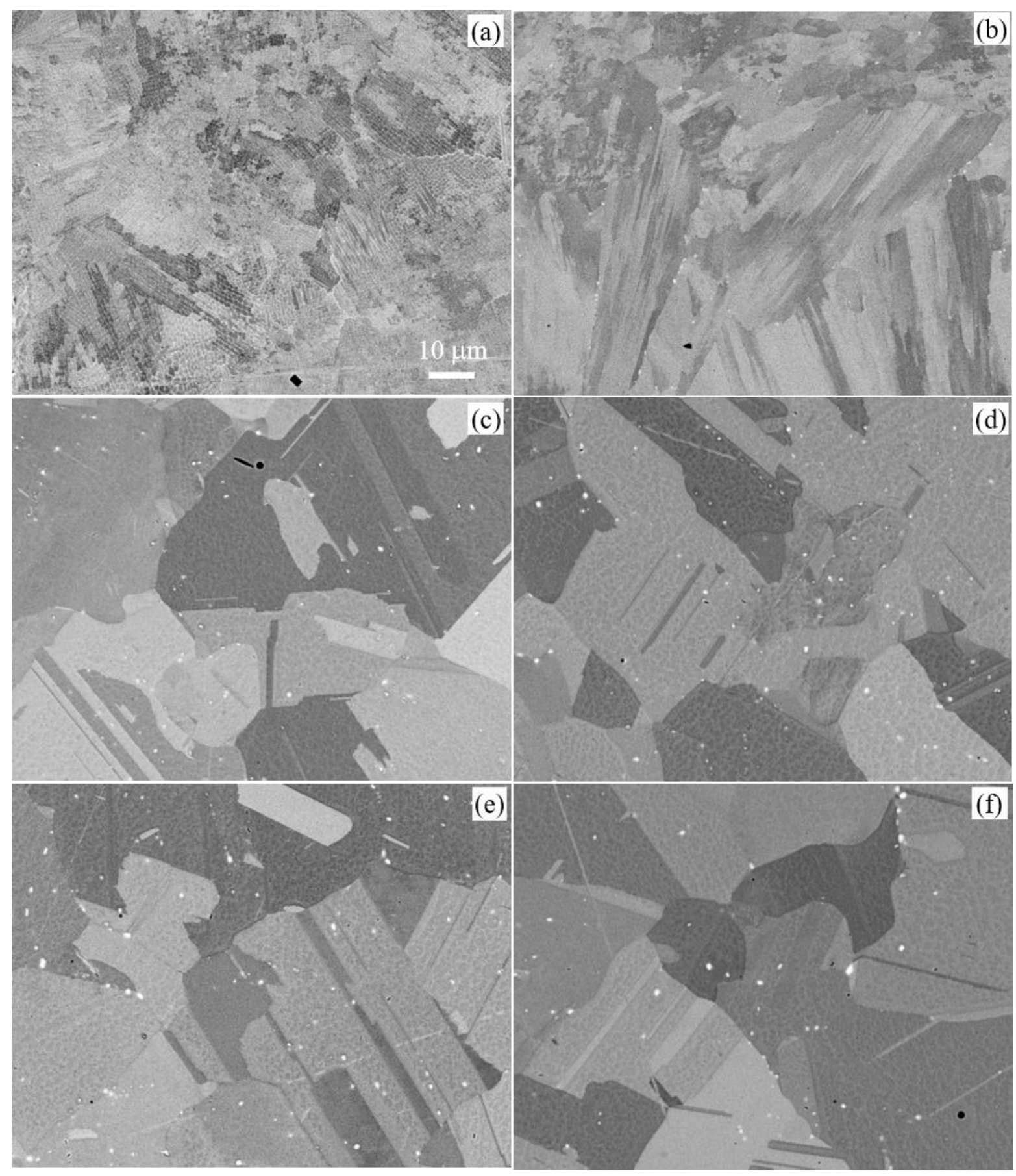

Fig. 2. SEM electron backscatter images: (a) as-printed, (b) ST1, (c) ST3, (d) ST6, (e) ST9 and (f) ST16. The white spots in the images are carbides (mainly NbC) particles; the darker spots are TiN or Al-rich particles, depending on the morphology. Al-rich particles are usually circular in shape. Note: Since the imaged were recorded at the same magnification, the scale bar shown in (a) is applicable for the rest of the images.

Although the SEM image of ST3 shown in Fig. 2 (c) is identical with the images of ST6, ST9 and ST16, there are still some remnant subgrains that are revealed by TEM analysis. The BF-TEM image in Fig. 3 (b) shows some of the subgrains in certain regions of the sample that persisted the 3 $\mathrm{h}$ of solid solution heat treatment. Like ST1 (Fig. 3a), the subgrain boundaries of STA3 appear more well-defined than that of the as-printed state. As it has been pointed out $[6,14]$ and shown in figures 
1 and 8, the subgrain boundaries of the as-printed Inconel 718 are decorated with high density of entangled dislocations and segregated phases. The thermal energy supplied during the $3 \mathrm{~h} \mathrm{ST}$ could dissolve most of the segregated phases and annihilate most of the dislocations. In addition, a greater number of the subgrains were eliminated, and some others were grown by coalescence as shown in Fig. 3. The 3 hours of ST is thus not long enough to supply enough energy for eliminating the subgrains completely.

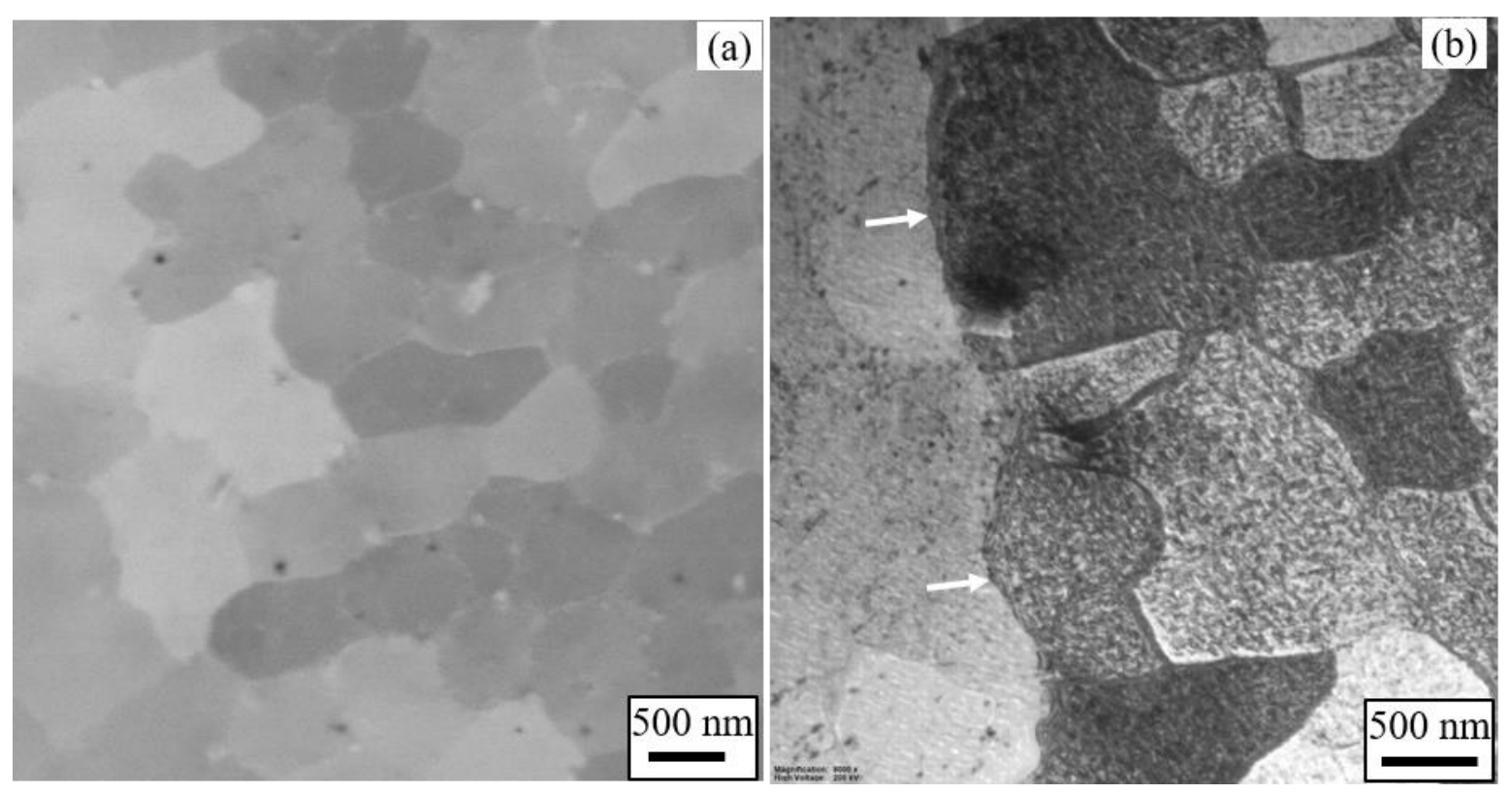

Fig. 3. Subgrain boundaries after heat treatment (a) electron backscatter image of ST1 and (b) TEM BF image of STA3. The tiny white spots in the subgrain boundaries in (a) are undissolved Laves/carbide phase. The arrows in (b) indicate a grain boundary. The rest are subgrain boundaries.

The formation of subgrains in L-PBF-Inconel 718 is believed to be the consequence of the repeated expansion/compression that occurred during the printing process. Due to the layer by layer building of the material, each of the deposited layer experiences repeated heating and cooling that build-up stresses in the material. The resulting high strains normally leads to emerging of high density of dislocations which are related to the amount of stresses developed as a result of repetitive heating and cooling process. Under the prevailing stresses, the dislocations tend to organize themselves into low energy states that form walls of dislocations inside a given grain. These walls of dislocation thus divide the grains into sections that differ from each other by low angle misorientation to form subgrains. The dislocations are also entangled around the Laves particles formed by segregation of heavier elements, such as $\mathrm{Nb}$, Mo and Ti. Most of the dislocations are annihilated during the solid solution heat treatment and left behind thinner subgrain boundaries than before as shown in Fig. 3 . As stated above, the $3 \mathrm{~h}$ hold time at $1100{ }^{\circ} \mathrm{C}$ of ST is not long enough to eliminate the entire subgrains. This substructure cannot be totally eliminated even after $7 \mathrm{~h}$ of ST as we have been reported previously $[6,14]$. On the other hand, we didn't observe the remnants of the subgrains in the sample ST for $9 \mathrm{~h}$ after having examined multiples of TEM images. The complete elimination of the subgrains in L-PBF deposited Inconel 718 is thus believed to be between 7 and 9 hours of ST at 1100 ${ }^{\circ} \mathrm{C}$.

Precipitates that are mainly rich in $\mathrm{Nb}, \mathrm{Mo}, \mathrm{Ti}$ and $\mathrm{C}$ with variable dimensions and quantities were observed in the samples solid solution heat treated along the grain boundaries as well as inside 
the grains. Generally, the primary phases of $\mathrm{MC}(\mathrm{M}$ stands for $\mathrm{Nb}, \mathrm{Ti}, \mathrm{Cr}, \ldots)$ and $\mathrm{TiN}$ in Inconel 718 cannot be dissolved at the ST temperature as pointed out by Radavich [2]. These phases are also found in AP and in all the ST samples. The carbide phases are stable at the ST temperature since their fusion temperatures are higher than that of the ST. The Ti-rich particles are mostly irregular in shape, but with straight edges as they appear in electron backscattered SEM images. The concentration level of $\mathrm{Ti}$ in such particles is around 80-weight percent. The rest of the composition is mainly nitrogen and it can thus be a phase containing Ti-N system. The Nb-rich particles are preferentially forming carbide phases. The particles with circular shape are usually rich in $\mathrm{Al}, \mathrm{O}$ and $\mathrm{Ti}$. These particles/phases in the L-PBF-Inconel 718 are practically undissolved even at $1250^{\circ} \mathrm{C} / 7 \mathrm{~h}$ of solid solution heating [14].

\subsubsection{Annealing twins in STA samples}

The samples that were solid solution heat treated for $3-24$ hours at $1100{ }^{\circ} \mathrm{C}$ appear to have similar grain structures as shown in Fig. 2 (c) through (f). The images in general illustrates changes in microstructure compared to the as-printed state. Consequently, the grains were grown substantially, but accompanied with evolution of large quantities of annealing twins during ST. Further study of the annealing twins is thus important since they have positive or negative impacts on material properties. Annealing twins in the fcc materials can be described as a 60 -degree rotation about a $\langle 111\rangle$ crystal axis of parent grain, with a tolerance angle of $8.66^{\circ}$, proposed by Brandon's criterion for twin boundaries [15]. Quantification of annealing twin density $\left(\mathrm{N}_{\mathrm{L}}\right)$ can be calculated according to equation (1).

$N_{L=} \frac{L_{t b} \cdot 2}{A \cdot \pi}$

Where $\mathrm{L}_{\mathrm{tb}}$ is the total twin boundary length in each section of area, A. The image quality (IQ) of EBSD maps for two of the STA samples that exhibit grain boundaries and twin boundaries are shown in Fig. 4. The twin boundaries are shown in red lines, whereas the black lines are for grain boundaries. The average grain size estimation is based on the histogram analysis data used by TSI/OIM software in the EBSD system. The average grain size, diameter (D) can be computed using equation 2 [16].

$\mathrm{D}=\frac{\sum_{\mathrm{i}} \mathrm{A}_{\mathrm{i}} \cdot \mathrm{D}_{\mathrm{i}}}{\sum_{\mathrm{i}} \mathrm{A}_{\mathrm{i}}}$

Where $D_{i}$ is the average diameter of the $i^{\text {th }}$ grain from a certain section of the image with an area $A_{i}$. The calculated annealing twin densities as a function of hold time for all the samples that were solid solution heat treated at $1100{ }^{\circ} \mathrm{C}$ are presented in Fig. 5. Shown here, only a few twins were formed after one hour of ST heating (STA1). These twins are formed near/inside bigger grains, which were evolved during merging of the smaller grains with the bigger ones. However, the quantity of the annealing twins formed is tremendously increased during the $3 \mathrm{~h}$ (STA3) of solid solution heat treatment (Fig. 4b \& 5b). 


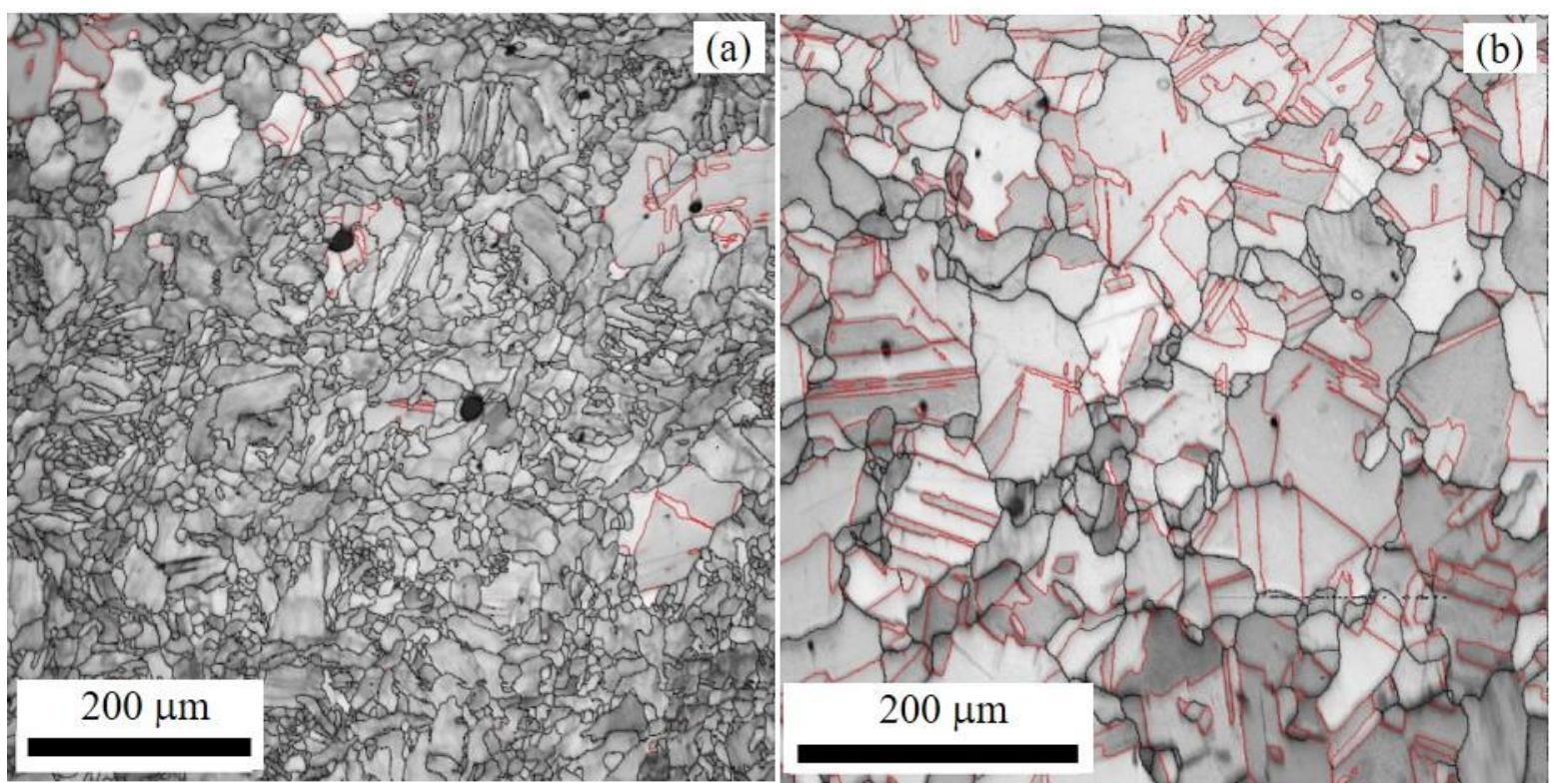

Fig. 4. EBSD-IQ maps showing grain boundaries (black lines) and twin boundaries (red lines): (a) STA1100-1 h (STA1), (b) STA1100-3 h (STA3).

Fig. 5(a) depicts the sharp rising of annealing twin density from about $5 \mathrm{~mm}^{-1}$ to $35 \mathrm{~mm}^{-1}$, corresponding to $1 \mathrm{~h}$ (STA1) and $3 \mathrm{~h}$ (STA3) solid solution heat treatments. The grain growth behaviour is also so large from $1 \mathrm{~h}$ to $3 \mathrm{~h}$ as shown in Fig. 5(b). This however do not show dependency of twin density on hold time. The dramatic increment of the twin density is rather caused by recrystallization than the hold time. Much of the stresses are released through dislocation annihilation and dissolution of the primary phases during the $3 \mathrm{~h}$ of solutioning heat treatment. As pointed out in previous report [14], the $1 \mathrm{~h}$ solid solution heat treated L-PBF-Inconel 718 at $1100{ }^{\circ} \mathrm{C}$ is in recovery stage and possess high stored energy due to unreleased stresses. Because of this, the grain structures of STA1 is very identical with that of AP (see Fig. 2). The twins formed in STA1 as shown in Fig. 4 (a) are only near or inside bigger grains. It seems that the merging of the nearby smaller grains with the existing bigger grains is believed to be the onset sites for the twining in STA1. After $3 \mathrm{~h}$ of annealing, however, much of the stresses are released and led to recrystallized microstructure, grain growth and twin formation. It means that a $1 \mathrm{~h}$ (STA1) heat treatment is not long enough to promote the formation of annealing twins significantly. Nevertheless, the twin density nearly remains the same for the hold time of ST between $6 \mathrm{~h}$ to $24 \mathrm{~h}$ (Fig. 5 (a)). This may indicate that solid solution heat treatment longer than $6 \mathrm{~h}$ has little to do for increasing the number of annealing twins. Consequently, most of the annealing twins were formed by recrystallization process [17] during the $3 \mathrm{~h}$ of ST that involved much of the relaxation of the stresses.

Metals/alloys fabricated with AM methods are known with high residual stresses that contain high amount of energies. Hence the microstructure of the as-printed state is a favorable condition for recrystallization and formation of annealing twins during ST. As a driving force, the high energy gradient stored in the strained microstructure allows higher grain boundary (GB) migration that promotes the formation of twins [17, 18]. The driving force is thus considered one of the key factors that affects twinning process during annealing. Further annealing longer than $3 \mathrm{~h}$ induced little increment in the number of twins as compare to that of STA3 as shown in Fig. 5(a). With reduction of stresses by heat treatment, recrystallization rate is reduced, and the rate of twin formation becomes very slow too. This effect is more illustrated in the plot of twin density as a function of grain size shown in Fig. 5 (c). The data points shown with artistic in the plot is due to the $1 \mathrm{~h} \mathrm{ST}$ (STA1). Here the twin density is proportionally increasing with grain size from $1 \mathrm{~h}$ to $3 \mathrm{~h}$ during which the rate of 
recrystallization was so high. However, once recrystallization is close to completion (after $3 \mathrm{~h}$ of ST), the rate of twin evolution reduced tremendously, which is in agreement with literature $[12,17,19]$. For the samples ST for 3 to $24 \mathrm{~h}$, the trend line shows a decreasing tendency of twin density as grain size increases. Two possible mechanisms are stated by Yuan and co-authors [19] to show the inverse correlation between twin density and average grain size. Smaller grains contain several twin boundaries that could be consumed by bigger grains during grain growth, that clearly reduce the number of twins. In addition, twin density can be reduced due to migration of incoherent twin boundaries in a direction that reduce the twin length and total interfacial energy.

(a) Twin density

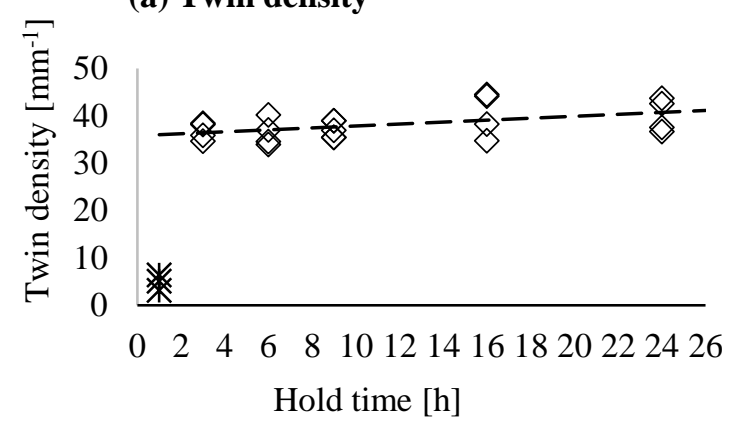

(b) Grain size

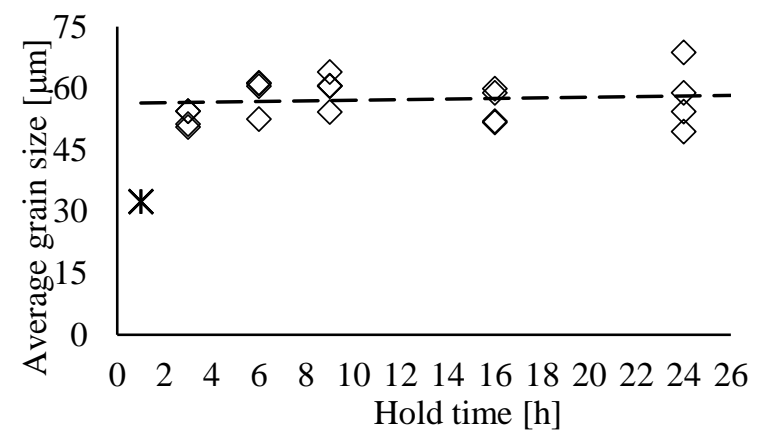

(c) Twin density vs. grain size

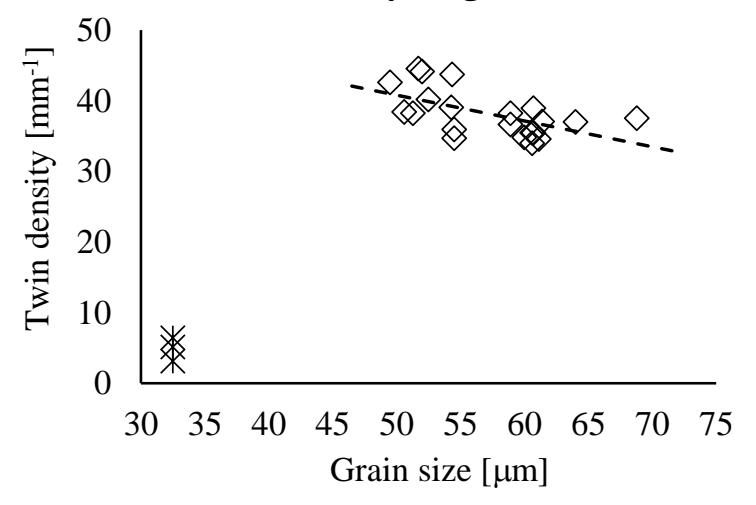

Fig. 5. Annealing twin density (a) and (b) average grain diameter as a function of hold time and (c) twin density vs. grain size.

Like twin density, the samples ST longer than $6 \mathrm{~h}$ did not show significant variations in the average grain sizes as it is revealed in Fig. 5b. In other words, solid solution heat treatment of L-PBFInconel 718 at $1100{ }^{\circ} \mathrm{C}$ from about 6 to $24 \mathrm{~h}$ of hold time do not lead to significant grain coarsening. Of course, STA24 exhibits more grain coarsening than the rest of the samples as shown in the wider variations of the average grain diameters for different regions in the sample (Fig. 5b), although the 
average size is nearly the same as that of the rest of the samples. It should also be noted that the twins were formed entirely during the solid solution heat treatment, and not during the aging process. Twins are less likely formed when aging since the temperature is not high enough to induce such structural changes in the L-PBF-Inconel 718. Hence, the quantity of twins in ST sample generally remain the same after aging treatment (STA). Furthermore, the current study illustrates that at $1100{ }^{\circ} \mathrm{C}$ of ST and hold times longer than $6 \mathrm{~h}$, the annealing twins maintain their thermal stability. So, in order to suppress the formation of annealing twins, the ST temperature should be set furthest from $1100{ }^{\circ} \mathrm{C}$ or ST for short duration $(\sim 1 \mathrm{~h})$ at $1100{ }^{\circ} \mathrm{C}$.

\subsubsection{Effects of aging}

\subsubsection{Solid solution and aging heat treatments (STA)}

Following the solid solution heat treatments at $1100{ }^{\circ} \mathrm{C}$, the samples were subjected to the two-step aging (at $760{ }^{\circ} \mathrm{C}$ for $10 \mathrm{~h}$ and then at $650{ }^{\circ} \mathrm{C}$ for another $10 \mathrm{~h}$ ). The grain structures of the ST and STA samples analyzed with SEM are quite similar since the thermal energy supplied at the aging temperature is not enough for promoting grain growth. However, new phases are precipitated during the aging heat treatment regime. These are $\gamma^{\prime \prime}\left(\mathrm{Ni}_{3} \mathrm{Nb}\right)$ and $\gamma^{\prime} \mathrm{Ni}_{3}(\mathrm{Nb}, \mathrm{Ti}, \mathrm{Al})$, which are mostly elliptical and spherical, respectively, in morphology. The temperature range for precipitation of $\gamma^{\prime \prime}$ and $\gamma^{\prime}$ phases are $704-899^{\circ} \mathrm{C}$ and $593-704^{\circ} \mathrm{C}$, respectively [2]. Similarly, nucleation of $\gamma^{\prime \prime}$ requires at least 4 wt. $\%$ of $\mathrm{Nb}$, while $\gamma^{\prime}$ can be formed with $\mathrm{Nb}$ concentration below 4 wt. \% [2].

Typical TEM images that reveal details of the microstructure of the STA samples are shown in Fig. 6. The SAD pattern shown in Fig. 6(a) is recorded with the matrix oriented in the $\langle 001\rangle$ zone axis. The strong spots in the diffraction pattern are reflections from the austenite $(\gamma)$ matrix. The superimposed weaker spots are super lattice reflections of the $\gamma^{\prime \prime}$ and $\gamma^{\prime}$ phases. Three variants of $\gamma^{\prime \prime}$ precipitates on the $\{100\}$ planes form the superposition of the different patterns in the SAD. These variants are based on $\langle 100\rangle \gamma^{\prime \prime},\langle 010\rangle \gamma^{\prime \prime}$ and $\langle 001\rangle \gamma^{\prime \prime}$ orientations. The dark field (DF) image of Fig. $6(b)$ is from the $\{002\}_{\gamma^{\prime \prime}}$ reflection in $\langle 100\rangle_{\gamma^{\prime \prime}}$ and the $\{101\}_{\gamma^{\prime \prime}}$ reflection in $\langle 010\rangle \gamma^{\prime \prime}$ zone axis. Similarly, the DF images shown in Fig. 6(c) and (d) are recorded from similar spots of the same SAD. The reflections from the $\gamma^{\prime}$ precipitates (primitive cubic) are overlapped with $\gamma$ (fcc) reflections. For the reasons explained in $[13,20]$, only a few of the super lattice reflections are common to both $\gamma^{\prime \prime}$ and $\gamma^{\prime}$ precipitates. In this case, the $\{100\}_{\gamma^{\prime}}$ and $\{002\}_{\gamma^{\prime \prime}}$ type reflections in $\langle 001\rangle_{\gamma}$ orientation are superimposed. The DF image obtained from the circled spot shown in Fig. 6(d) belongs to the reflections from both precipitates. The two precipitates can then be distinguished from the DF image without ambiguity. The $\gamma^{\prime}$ precipitates are spherical whereas the $\gamma^{\prime \prime}$ precipitates are mostly elliptical in morphology. The two phases sometimes fused together and form compact morphology. White arrows in Fig. 6(d) indicate examples of composite $\gamma^{\prime}$ and $\gamma^{\prime \prime}$ precipitates. Large quantity of fused $\gamma^{\prime \prime}$ and $\gamma^{\prime}$ is obtained after longer aging time [21]. Detailed analysis is available in references [6, 20, 22].

The distribution of the $\gamma^{\prime \prime}$ precipitate appear homogeneous and in large quantity for the STA samples as shown in Fig. 6(b) and (c). On the other hand, the hardening precipitates in DA sample (Fig. 6(d)) are rare in quantity and the subgrain boundary regions contain Laves and other defects. Subgrain boundaries of the DA sample are labeled with letter ' $L$ ' in Fig. 6(d). Similarly, the microstructure of DA and AP samples are compared in Fig. 7. The subgrains of DA were retained and most of the components in the subgrain boundaries were also remain undissolved. 


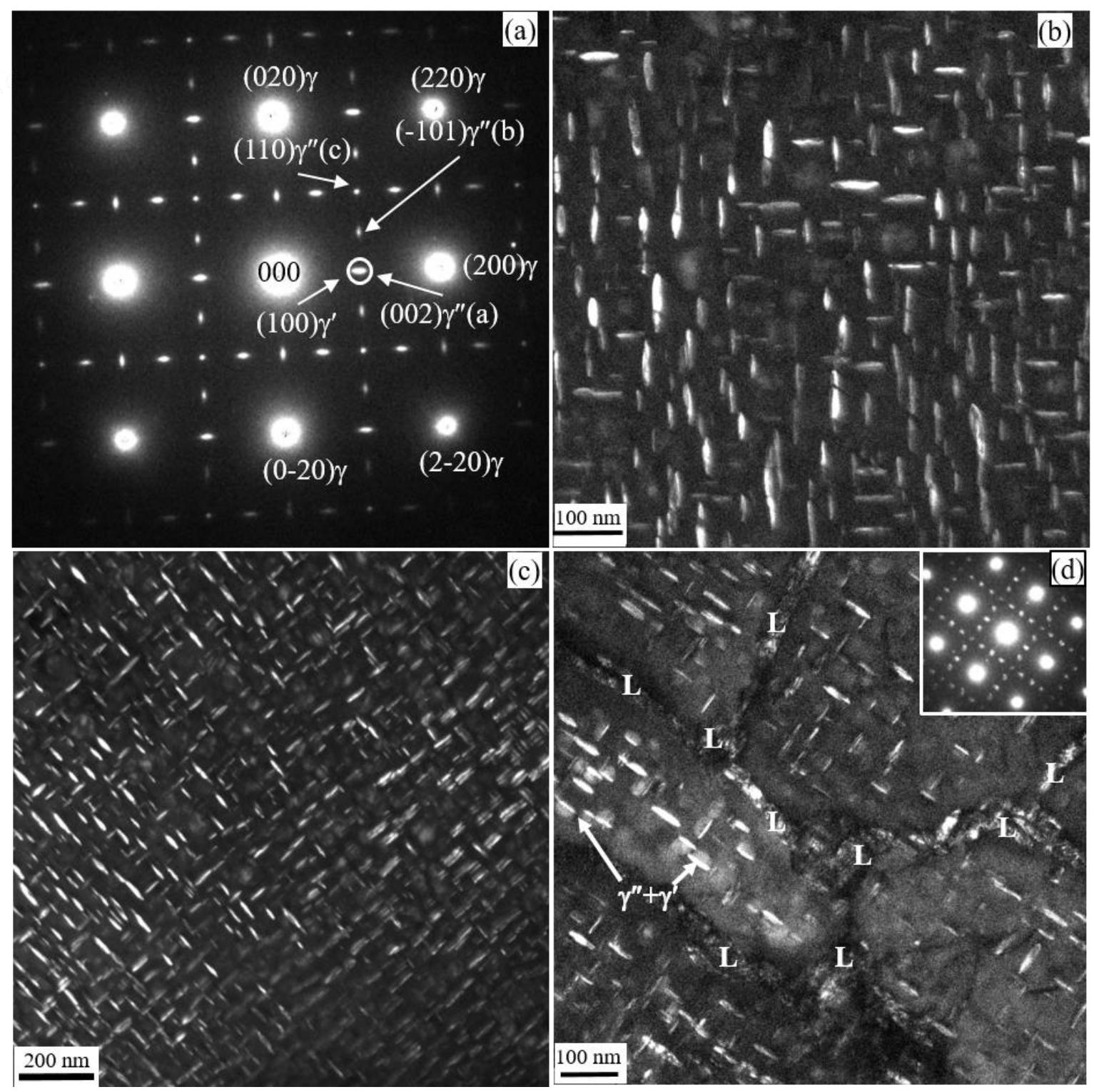

Fig. 6. TEM images of aged samples: a) SAD in [001] zone (b) DF image of STA16 using the circled superlattice spot in (a), (c) DF image of STA9 and (d) DF image of DA. The inset in (d) is the corresponding diffraction pattern of the image. The subgrain boundary regions with undissolved Laves and lattice defects are indicated by the latter ' $L$ ' in (d). The labels (a), (b) and (c) in the SAD in (a) are referring to the orientations of [001], [010] and [001], respectively.

\subsubsection{Direct aging (DA)}

Aging temperature is generally not high enough to initiate recrystallization in L-PBF-Inconel 718 and its effects on grain growth is thus insignificant. The grain structure of the direct aged sample is qualitatively the same as that of the as-printed as shown in Fig. 7. The sub grains and the segregated particles in the subgrain boundaries remain undissolved after aging. The white spots seen in both images are largely the Laves phase. There is, however, some slight differences in microstructure between AP and DA based on the analysis of high magnification SEM images shown in Fig. 8. The black arrows are pointing to some of the bigger Laves particles located along the subgrain boundaries 
in both (a) for AP and (b) for DA. After aging, very fine and needle-like precipitates were evolved from the segregated phases located along the subgrain and grain boundaries. The white arrows in Fig. 8 (b) indicates some of these needle-like precipitates formed near/along the subgrain boundaries. The Laves phase, whose $\mathrm{Nb}$ concentration is high, appears as the nucleation site for the needle-like delta $(\delta)$ precipitates. The $\delta$ phase is an orthorhombic structure with the same formulation $\left(\mathrm{Ni}_{3} \mathrm{Nb}\right)$ as that of the $\gamma^{\prime \prime}$ phase. The precipitation of $\delta$-phase could start at relatively lower temperatures $(700-900$ ${ }^{\circ} \mathrm{C}$ ) [2], but the optimum precipitation temperature is somewhere between 870 and $1010{ }^{\circ} \mathrm{C}[2,6]$. Slama et. al. [3] have also observed similar growth of the $\delta$ precipitates even at lower temperature $\left(550{ }^{\circ} \mathrm{C}\right)$, but after very long hold time $(50 \mathrm{~h})$. Nucleation of $\delta$ phase requires $6-8 \mathrm{wt} . \% \mathrm{Nb}[2]$, and it is therefore reasonable to observe $\delta$ precipitates in the subgrain boundaries than inside subgrains. The formation of $\delta$ can potentially reduce ductility and toughness due to its embrittlement nature [2] besides depleting $\mathrm{Nb}[3,23]$ that otherwise be consumed for precipitation of strengthening phases. Furthermore, formation of $\delta$ particles weaken the creep strength of Inconel 718 at elevated temperature test [24].

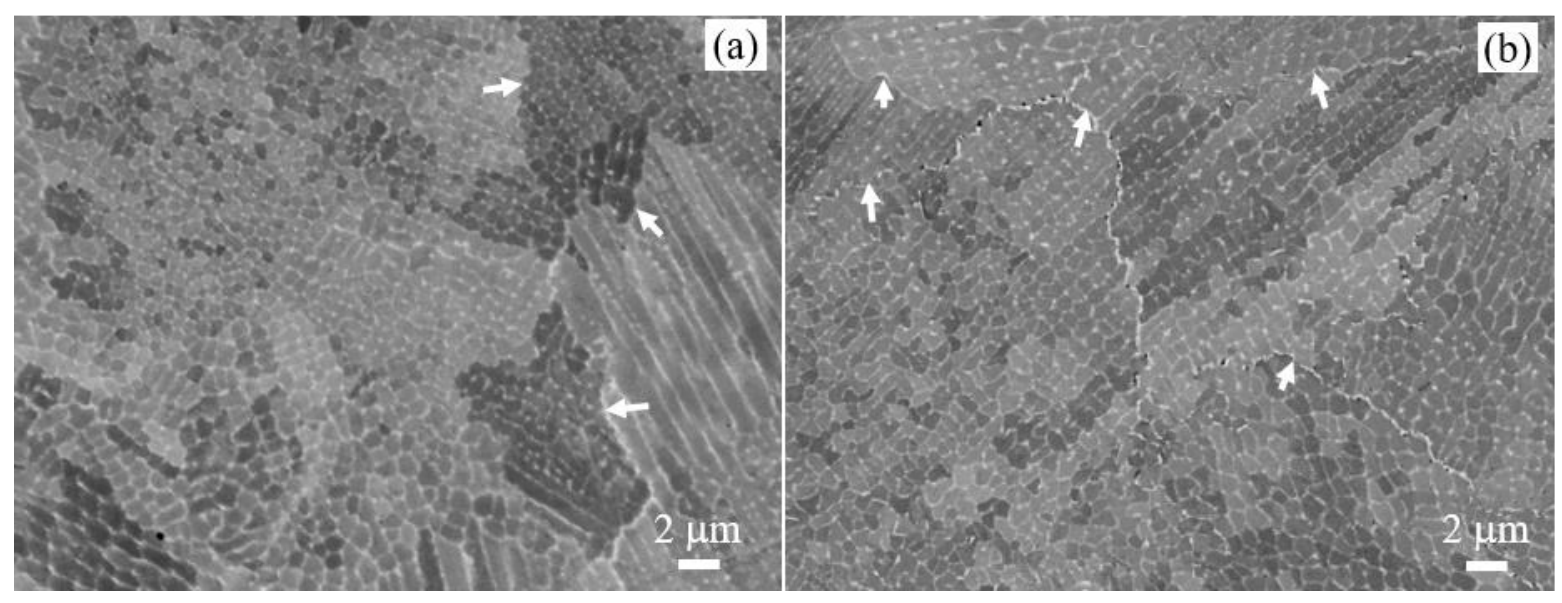

Fig. 7. Electron backscatter SEM images: (a) as-printed and (b) direct-aged samples. The arrows are pointing to the grain boundaries in both images.

To assess the distribution of $\mathrm{Nb}$ in different regions of the samples, numerous EDS data were recorded, and average values were calculated. The result shows that the local concentration of $\mathrm{Nb}$ is different for the AP and DA samples. The average concentration of $\mathrm{Nb}$ along the subgrain boundaries is more than $7 \mathrm{wt}$ \% for both AP and DA but showed different concentrations inside their subgrains. $\mathrm{Nb}$ inside the subgrains of AP and DA are 2.61 and 2.96 wt. \%, respectively. The level of Nb in DA is larger than in the AP by about $0.35 \mathrm{wt} . \%$. Nb tend to diffuse from the high concentration region in the subgrain boundaries to the core of the subgrain region during aging. This makes the nonboundary regions of DA richer in $\mathrm{Nb}$ (where $\gamma^{\prime \prime}$ and $\gamma^{\prime}$ precipitated) than that of the AP. On the other hand, the average concentrations of $\mathrm{Nb}$ in the non-intergranular region of the ST and STA samples are larger than AP or DA samples. For example, the average $\mathrm{Nb}$ level in the non-intergranular region of ST16 is 3.84 wt. \%, which is about 1 wt. \% larger than that of AP. The increment of of Nb level inside the grains after the ST is due to the dissolution (partially or completely) of the Laves phase from the subgrain boundaries. Obviously, the amount of $\mathrm{Nb}$ that are readily available for precipitation in ST16 is more than that of AP. Similarly, the concentration of Nb in the non-intergranular region of STA16 is $3.84 \mathrm{wt}$. \% (about $0.9 \mathrm{wt}$. \% compared to DA). The composition difference in Nb between the STA and DA samples is clearly proportional to the corresponding quantities of the hardening precipitates formed. Evidently, the distribution difference visualized in the hardening precipitates 
shown in Fig. 6 (b) (STA16) and (d) (DA) agrees well with the relative concentration differences in $\mathrm{Nb}$.

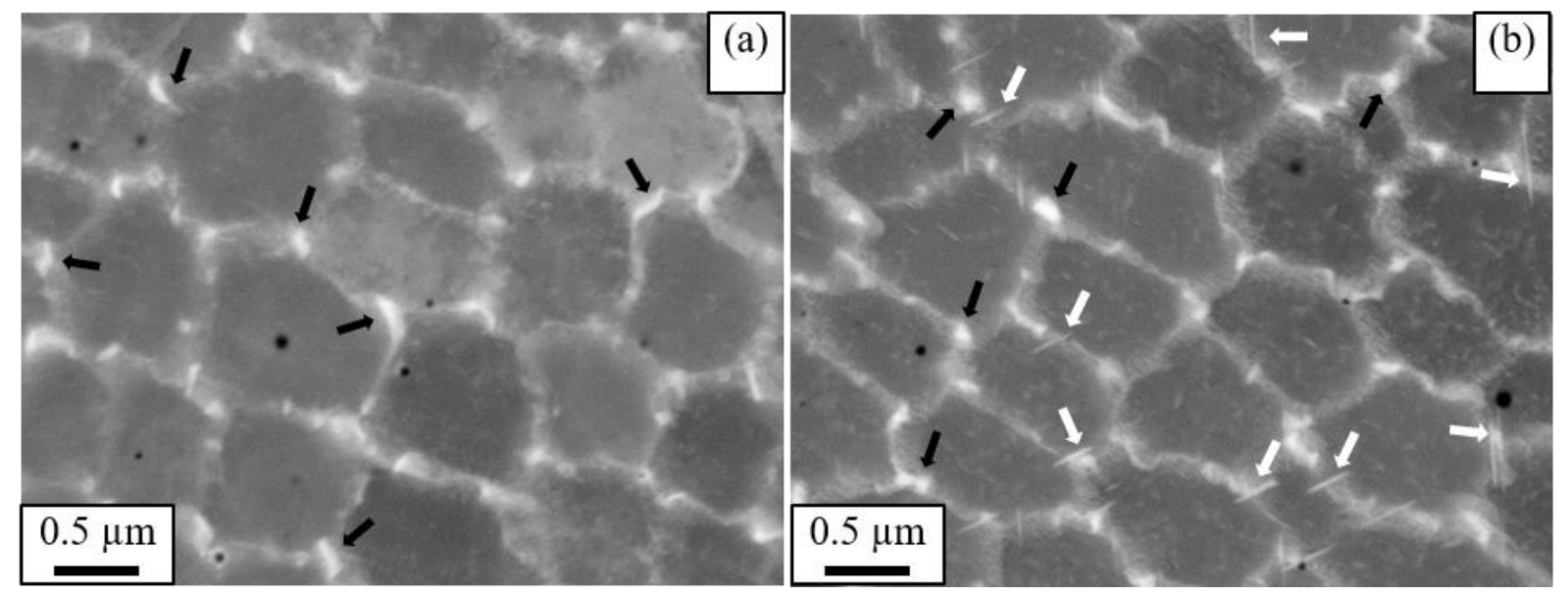

Fig. 8. High magnification image of SEM: (a) as-printed and (b) direct aged samples. Black arrows are indicating Laves phase. The white arrows are pointing to the $\delta$ precipitates.

Direct aging is not a preferred way of hardening L-PBF-Inconel 718 although beneficial economically as it bypasses solid solution heat treatment stage because of the prevailing high stresses in the microstructure. The optimum mechanical property is thus realized when large quantities of hardening precipitates are formed and distributed evenly in the matrix. This can be achieved by performing solid solutioning heat treatments at appropriate temperature and hold time before aging.

\subsection{Phase identification with $\mathrm{X}$-Ray diffraction}

The X-ray diffractogram for AP, ST3 and STA3 samples are shown in Fig. 9 (a), (b) and (c), respectively. The strong peaks are indexed to the fcc structure, 111, 200, 220, 311 and 222, corresponding to the austenite $(\gamma)$ phase. The primary phases in AP, such as Laves and carbides are too small in volume fraction compared to the austenite phase, so that the resulting peaks are too weak. The reflections from the $\gamma^{\prime \prime}$ appear on the lower angle side of the $\gamma$-fcc peaks of STA3. These are indicated with inverted triangles in Fig. 9 (c), that are indexed to a bct structure. The Miller indices of these peaks are 004, 204, 224, and 116. The $112 \gamma^{\prime \prime}$ diffraction peak is however very close (overlapped) to the $111 \gamma$ peak. The $\gamma^{\prime}$ phase is smaller in size and in quantity compared to $\gamma^{\prime \prime}$ phase and consequently their peaks are too weak. In addition, since $\gamma^{\prime}$ is a primitive cubic structure, most of its peaks are overlapped with the strong fcc $(\gamma)$ peaks. In general, the X-ray result agrees well with the TEM analysis that unambiguously identified the $\gamma^{\prime \prime}$ and $\gamma^{\prime}$ phases using combination of diffraction patterns and dark filed images. 


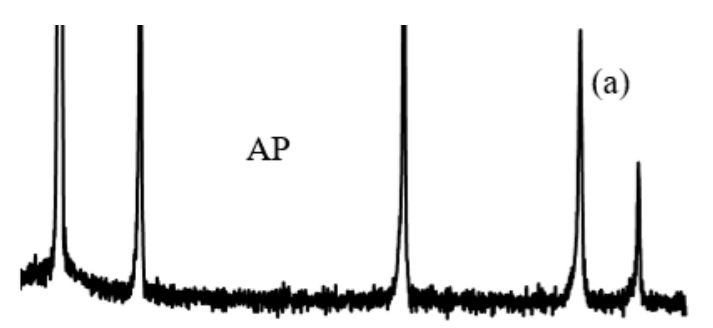

(b)

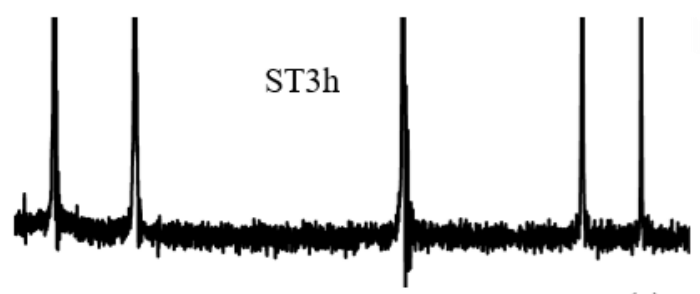

(c)

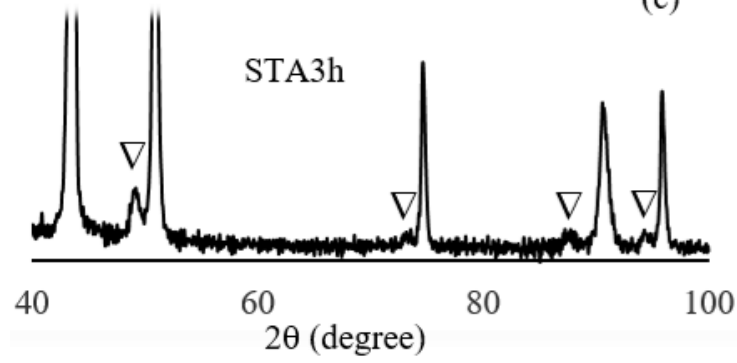

Fig. 9. X-Ray diffractograms of (a) AP, (b) ST3 and (c) STA3. The strong peaks are indexed to fcc structure $(\gamma)$, whereas, the inverted triangles are pointing to the peaks indexed to tetragonal structure ( $\gamma^{\prime \prime}$ phase).

Additional information can be obtained by examining position and width of the X-ray diffraction peaks. The hump/shoulder seen on the lower angle side of (111) $\gamma$ of AP peak, for example, could be due to Laves and/or carbide phases. The residual stresses in the lattice defects may also contribute to the hump. Apparently, these humps disappeared after the solid solution heat treatment as shown in Fig. 10 (ST6 vs. AP). The peak of the solid solution heat treated sample (ST6) became narrower compared to that of the AP, mainly, due to relief of stresses following recrystallization. The shift of STA6 peak to the high angle side relative to AP is also depicted in Fig. 10. The shift is clearly due to the formation of the tiny strengthening precipitates $\left(\gamma^{\prime}\right.$ and $\left.\gamma^{\prime \prime}\right)$ that enhance the strain in the matrix. Furthermore, redistribution of the alloy composition due to dissolution of the segregated primary phases may also contribute to the shift of the peaks. In addition, the STA6 peak is broader than the AP as well as ST6 peaks. Further broadening of the STA6 peak is believed to be due to the formation of the nano-sized precipitates $\left(\gamma^{\prime}\right.$ and $\left.\gamma^{\prime \prime}\right)$ after aging, which agrees with Scherrer's equation, that shows the inverse relationship between X-ray peak broadening and crystal size. 


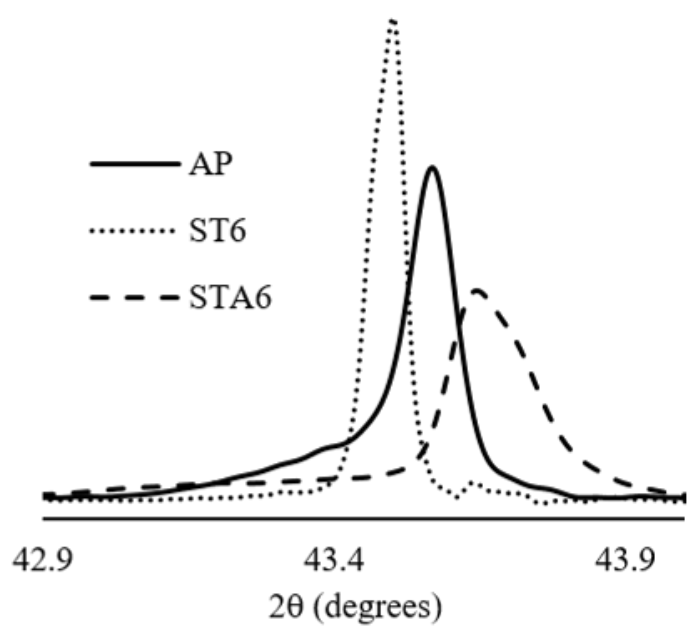

Fig. 10. High magnification plot of (111) $\gamma$ peak showing shift of peaks and variation of breadth after heat treatment.

\subsection{Vickers hardness measurement}

The average hardness of both ST and STA samples are given in Table 2. The data is also plotted and shown in Fig. 11 in order to visualize variation of hardness as a function of hold time. The hardness decreases with increasing hold time but tend to be the same for hold times longer than 6 hours. The hardness of the sample solution heat treated for $3 \mathrm{~h}$ is $200 \mathrm{HV}$, but lower for the other samples with longer hold times. The variation in hardness is associated with changes in microstructure following solid solution heat treatment. ST dissolves undesirable phases such as Laves and releasing age-hardening constituents ( $\mathrm{Nb}, \mathrm{Ti}$ and $\mathrm{Al}$ ) into the matrix. In addition, ST eliminates crystal defects, primarily, dislocation networks. As a result, the as-printed specimen (black bar) in Fig. 11 is harder than all the specimens that were subjected to ST. Clearly, the variation in hardness is proportional to the changes in microstructure as discussed elsewhere in the previous section. The hardness is decreasing with increasing hold time of ST and became nearly the same from $6 \mathrm{~h}$ to $24 \mathrm{~h}$. Depending on the hold time, the hardness decreases between 19 to $37 \%$ relative to that of AP. This is clearly associated with the degree of recrystallization that involves rearrangement and annihilation of dislocations and other lattice defects.

Table 2: Average hardness (HV) of as-printed, direct-aged, ST and STA samples.

\begin{tabular}{|c|c|c|c|c|}
\hline \multirow{2}{*}{$\begin{array}{l}\text { Sample/ } \\
\text { Hold time }\end{array}$} & \multicolumn{4}{|c|}{ Hardness [HV] } \\
\hline & $\mathrm{AP}$ & ST & STA & $\% \Delta \mathrm{HV}$ \\
\hline AP & $308 \pm 5$ & & & \\
\hline DA & & & $446 \pm 4$ & 45 \\
\hline $1 \mathrm{~h}$ & & $249 \pm 4$ & $456 \pm 4$ & 49 \\
\hline $3 \mathrm{~h}$ & & $200 \pm 3$ & $444 \pm 5$ & 45 \\
\hline $6 \mathrm{~h}$ & & $195 \pm 3$ & $439 \pm 3$ & 43 \\
\hline $9 \mathrm{~h}$ & & $191 \pm 3$ & $442 \pm 6$ & 44 \\
\hline $16 \mathrm{~h}$ & & $192 \pm 3$ & $439 \pm 3$ & 43 \\
\hline $24 \mathrm{~h}$ & & $192 \pm 5$ & $420 \pm 5$ & 36 \\
\hline
\end{tabular}

Note: $\% \Delta \mathrm{HV}$ is the percentage increment in hardness after aging compared to the hardness of the as-printed. 


\section{Hardness measurements}

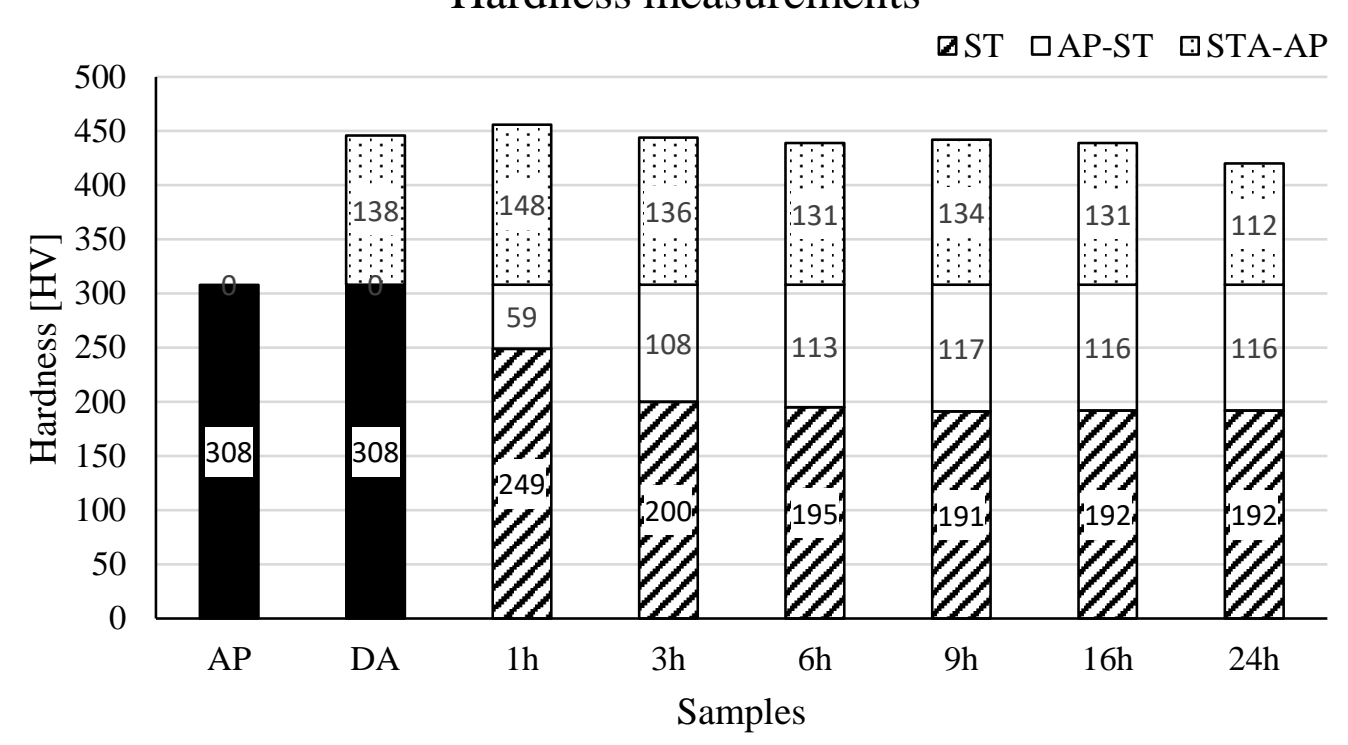

Fig. 11. Average Vickers hardness: The black bar represents the hardness of the as-printed sample. The patterned bars show the hardness after ST, whereas the white bars represent the amount of hardness decreased due to ST. The dotted bars represent the increment in hardness relative to AP after aging. The increment in hardness due to the hardening precipitates is the sum of the white and dotted bars. The numbers in the bars are the average values of the hardness in HV.

The direct aged sample exhibits increment in hardness by about $45 \%$ relative to the as-printed state. The gain in hardness is clearly due to the precipitation of hardening phases, $\gamma^{\prime \prime}$ and $\gamma^{\prime}$. Since DA was not solution heat treated, $\mathrm{Nb}$ tends to diffuse slowly from the high concentration region (Laves inside the subgrain boundaries) into the solid solution matrix during aging heat treatment. This would raise the level of $\mathrm{Nb}$ slightly inside subgrains and readily available for the precipitation of $\gamma^{\prime \prime}$ and $\gamma^{\prime}$ precipitates.

To assess the contribution of age hardening, it is interesting to compare the increment in hardness (sum of the white and dotted bars in Fig. 2) between the samples. After aging, maximum increment in hardness was obtained for STA9, the sample that was subjected to $9 \mathrm{~h}$ of ST and aged. Comparing the different STA samples, the smallest increment in hardness reinforced by the precipitation hardening is due to STA1. The difference between these two samples (STA1 \& STA9) in hardness is assumed to be the result of the differences in the degree of recrystallization. After $6 \mathrm{~h}$ of ST, the hardness is dropping slightly up to $9 \mathrm{~h}$, but no significant difference between that of $9 \mathrm{~h}$ and $24 \mathrm{~h}$. It means, the quantity of dislocation is dropped considerably, and recrystallization essentially attains strain-free state after $9 \mathrm{~h}$ of solid solution heating. Therefore, based on the microstructure analysis and hardness measurement, complete elimination of subgrains in L-PBFInconel 718 can be achieved after solid solution heat treatment for longer than $7 \mathrm{~h}$, but most likely less than $9 \mathrm{~h}$ at $1100^{\circ} \mathrm{C}$.

After aging, the gain in hardness is clearly due to the precipitation of the strengthening phases formed during aging. The effect of ST as stated elsewhere is to release residual stresses in the material and to dissolve Laves phase that contains elements such as $\mathrm{Nb}$ and $\mathrm{Al}$. The resulting effect is recrystallization and grain growth depending on the hold time, which affect hardness negatively as shown in Fig. 11 (black bar vs. patterned bars). The direct aged samples however exhibit increment in hardness without undergoing solid solution heat treatment. Clearly, the increment in hardness is due to the phases precipitated during age hardening. As shown in Fig. 11, the hardness gained after aging is larger for longer hold times than for the shorter hold times. The increment in hardness due 
to hardening precipitates is generally increasing with ST hold time, which could be related to the quantity of the hardening precipitates. STA24 however showed slightly lower hardness compare to the other aged samples. This might be due grain coarsening in certain regions of the sample, and it could also be due to other reasons that are not investigated in this study. The hardness of the sample subjected to ST for shorter duration (example STA1) is due to the combined effects of the undissolved lattice defects (e.g. dislocations) and the aging precipitates. Such samples are however known with lower ductility due to large amount of stresses and lattice defects compared to those samples being well recrystallized after sufficiently solid solution heat treated. To attain stress-free microstructure, it is therefore recommended to perform ST of L-PBF-Inconel 718 for hold time longer than $6 \mathrm{~h}$ at 1100 ${ }^{\circ} \mathrm{C}$ before aging.

\section{Conclusions}

The effects of solid solution heat treatment of L-PBF-Inconel 718 at $1100{ }^{\circ} \mathrm{C}$ at various hold times $(1,3,6,9,16$ or $24 \mathrm{~h})$ on the microstructure and hardness are investigated. Significant changes in grain structure occurred after $3 \mathrm{~h}$ and longer hold times. Complete annihilation of the subgrains is however observed after about $9 \mathrm{~h}$ of hold time. The complete strain free (without subgrains) recrystallized microstructure can be obtained after solid solution heat treatment for longer than $7 \mathrm{~h}$, but most likely less than $9 \mathrm{~h}$ at $1100{ }^{\circ} \mathrm{C}$. Generally, dissolution of the Laves phase and annihilation of dislocations preceded the elimination of the subgrain boundaries.

Depending on the amount of recrystallization and grain growth, the hardness of ST samples are decreasing with increasing hold time up to $6 \mathrm{~h}$, but becomes nearly the same for longer hold times. As expected, hardness is increased after aging up to $49 \%$ compared to that of as-printed. The maximum increment pertaining to the precipitation of the strengthening phases $\left(\gamma^{\prime \prime}\right.$ and $\left.\gamma^{\prime}\right)$ is obtained at the hold time of $9 \mathrm{~h}$ of ST. Considerable amount of dislocations is annihilated and strain-free recrystallization is essentially attained at the $9 \mathrm{~h}$ and longer solid solution heat treatment.

The microstructure of solid solution heat treated L-PBF-Inconel 718 at $1100{ }^{\circ} \mathrm{C}$ for more than 1 $\mathrm{h}$ hold time is characterized with high density of annealing twins. The annealing twins observed are largely recrystallization twins that were formed during the first few hours of ST and remain nearly constant if longer hold time is considered. To inhibit the formation of the annealing twins, the ST temperature should be chosen furthest from $1100{ }^{\circ} \mathrm{C}$.

Direct aged sample is nearly as hard as the STA samples, but it exhibits similar microstructure as that of the as-printed. The microstructure is nearly retained since the aging temperature is not high enough to undergo significant recrystallization. Direct aging is thus not recommended because of the retained lattice defects and phases that can potentially threatening other properties of the material.

The continuation of this work includes systematic investigations of the effects of annealing twins on the mechanical properties in connection with optimization of heat treatment process. Tensile strength, ductility and creep behavior analysis will be performed to determine if annealing twins are beneficial or not for the L-PBF-fabricated Inconel 718. Based on the results, temperature and hold time of solid solution heat treatment for achieving optimum microstructure and mechanical properties can then be proposed for further study.

\section{Acknowledgements}

The authors would like to thank Eivind Strømland and Tor Nordheim from PROMET AS for supplying the samples. 


\section{References}

[1] ASTM F3055-14a, Standard Specification for Additive Manufacturing Nickel Alloy (UNS N07718) with Powder Bed Fusion, 2014. www.astm.org. cited in 2019).

[2] J.F. Radavich, The physical metallurgy of cast and wrought alloy 718, The Minerals Material Society1989, pp. 229-240.

[3] C. Slama, C. Servant, G. Cizeron, Aging of the Inconel 718 alloy between 500 and $750{ }^{\circ} \mathrm{C}$, Journal of Materials Research 12(09) (1997) 2298-2316.

[4] S. Sui, H. Tan, J. Chen, C. Zhong, Z. Li, W. Fan, A. Gasser, W. Huang, The influence of Laves phases on the room temperature tensile properties of Inconel 718 fabricated by powder feeding laser additive manufacturing, Acta Materialia 164 (2019) 413-427.

[5] J.D. Verhoeven, Fundamentals of Physical Metallurgy, John Wiley \& Sons, New York, 1975.

[6] W.M. Tucho, V. Hansen, Characterization of SLM-fabricated Inconel 718 after solid solution and precipitation hardening heat treatments, Journal of Materials Science 54(1) (2019) 823-839.

[7] Y. Cao, P. Bai, F. Liu, X. Hou, Y. Guo, Effect of the Solution Temperature on the Precipitates and Grain Evolution of IN718 Fabricated by Laser Additive Manufacturing, Materials (Basel) 13(2) (2020).

[8] C. Li, B. Ma, Y. Song, K. Li, J. Dong, The Annealing Twins of Fe-20Mn-4Al-0.3C Austenitic Steels during Symmetric and Asymmetric Hot Rolling, Metals 8(11) (2018) 882.

[9] T.H. Chuang, C.H. Tsai, H.C. Wang, C.C. Chang, C.H. Chuang, J.D. Lee, H.H. Tsai, Effects of Annealing Twins on the Grain Growth and Mechanical Properties of Ag-8Au-3Pd Bonding Wires, Journal of Electronic Materials 41(11) (2012) 3215-3222.

[10] J. Miao, T.M. Pollock, J. Wayne Jones, Crystallographic fatigue crack initiation in nickel-based superalloy René 88DT at elevated temperature, Acta Materialia 57(20) (2009) 5964-5974.

[11] C.A. Stein, A. Cerrone, T. Ozturk, S. Lee, P. Kenesei, H. Tucker, R. Pokharel, J. Lind, C. Hefferan, R.M. Suter, A.R. Ingraffea, A.D. Rollett, Fatigue crack initiation, slip localization and twin boundaries in a nickelbased superalloy, Current Opinion in Solid State and Materials Science 18(4) (2014) 244-252.

[12] N. Bozzolo, M. Bernacki, Viewpoint on the Formation and Evolution of Annealing Twins During Thermomechanical Processing of FCC Metals and Alloys, Metallurgical and Materials Transactions A 51(6) (2020) 2665-2684.

[13] D.F. Paulonis, J.M. Oblak, D.S. Duvall, Pricipitation in Nickel-base alooy 718, Defense Technical Information Center1969.

[14] W.M. Tucho, P. Cuvillier, A. Sjolyst-Kverneland, V. Hansen, Microstructure and hardness studies of Inconel 718 manufactured by selective laser melting before and after solution heat treatment, Materials Science and Engineering: A 689 (2017) 220-232.

[15] D.G. Brandon, The structure of high-angle grain boundaries, Acta Metallurgica 14(11) (1966) 14791484.

[16] N. Bozzolo, N. Souaï, R.E. Logé, Evolution of microstructure and twin density during thermomechanical processing in a $\gamma-\gamma^{\prime}$ nickel-based superalloy, Acta Materialia 60(13-14) (2012) 5056-5066.

[17] Y. Jin, B. Lin, A.D. Rollett, G.S. Rohrer, M. Bernacki, N. Bozzolo, Thermo-mechanical factors influencing annealing twin development in nickel during recrystallization, Journal of Materials Science 50(15) (2015) 5191-5203.

[18] W. Wang, S. Lartigue-Korinek, F. Brisset, A.L. Helbert, J. Bourgon, T. Baudin, Formation of annealing twins during primary recrystallization of two low stacking fault energy Ni-based alloys, Journal of Materials Science 50(5) (2015) 2167-2177.

[19] Y. Jin, M. Bernacki, A. Agnoli, B. Lin, G. Rohrer, A. Rollett, N. Bozzolo, Evolution of the Annealing Twin Density during $\delta$-Supersolvus Grain Growth in the Nickel-Based Superalloy Inconel ${ }^{\mathrm{TM}} 718$, Metals $6(1)$ (2015).

[20] S.J. Hong, W.P. Chen, T.W. Wang, A diffraction study of the $\gamma^{\prime \prime}$ phase in INCONEL 718 superalloy, Metallurgical and Materials Transactions A 32A (2001) 1887-1901.

[21] R. Cozar, A. Pineau, Morphology of $y^{\prime}$ and $y^{\prime \prime}$ precipitates and thermal stability of inconel 718 type alloys, Metallurgical Transactions 4 (1973) 47-59. 
[22] M. Sundararaman, P. Mukhopadhyay, S. Banerjee, Some aspects of the precipitation of metastable intermetallic phases in inconel 718, Metallurgical Transactions A 23A (1992) 2015-2027.

[23] H. Qi, M. Azer, A. Ritter, Studies of standard heat treatment effects on microstructure and mechanical properties of laser net shape manufactured Inconel 718, Metallurgical and Materials Transactions A 40A (2009) 13.

[24] Y.-L. Kuo, T. Nagahari, K. Kakehi, The Effect of Post-Processes on the Microstructure and Creep Properties of Alloy718 Built Up by Selective Laser Melting, Materials 11(6) (2018) 13. 